\title{
ASSISTÊNCIA EM ENFERMAGEM NA PERSPECTIVA DA CLÍNICA AMPLIADA EM UNIDADE DE TERAPIA INTENSIVA
}

\author{
Luciana de F reitas CAM POSa, M arcia Regina A ntonietto da Costa M E L O ${ }^{\text {b }}$
}

\section{RESUMO}

E ste artigo tem como objetivo refletir sobre a assistência em enfer magem na per spectiva da clínica ampliada em U nidade de T erapia I ntensiva (UTI). 0 estudo car acteriza-se como refl exão. A ampliação da clínica prevê um ol har ao ser humano considerando seu aspecto biológico associado à subjetividade de cada caso em particular por meio de uma abordagem integral, interdisciplinar e compartilhada. F az-se necessário que ações conjuntas de uma equipe interdisciplinar modifiquem o cenário da UTI , local onde o modelo hegemônico historicamente se perpetua. $\mathrm{Na}$ enfermagem a responsabilidade com 0 indivíduo, seu bem-estar e 0 ambiente fazem parte de sua prática sendo possível uma participação efetiva e uma mudança da prática hegemônica para uma clínica ampliada.

Descritores: H umanização da assistência. U nidades de terapia intensiva. E quipe de assistência ao paciente. E quipe de enfermagem.

\section{RESUMEN}

E $n$ este artículo se pretende reflexionar sobre los cuidados de enfermería a la vista de la clínica ampliada en la U nidad de Cuidados I ntensivos $(\mathrm{U} C \mathrm{Cl})$. E I estudio se caracteriza por la reflexión. L a expansión dela dínica ofrece un vistazo a la hora de considerar su aspecto biológico humano de la subjetividad asociada a cada caso particular por un enfoque integral, interdisciplinaria y compartida. Son necesarios los esfuerzos conjuntos de un equipo interdisciplinario para modificar la configuración de la $\mathrm{U} \mathrm{Cl}$, donde históricamente se per petúa el modelo hegemónico. E n la enfermería la responsabilidad con el individuo, su bienestar y el medio ambiente son parte de su práctica puede ser una participación efectiva y una modificación de la práctica hegemónica de una clínica ampliada.

Descriptores: H umanización de la atención. U nidades de terapia intensiva. Grupo de atención al paciente Grupo de enfermería.

Título: A tención en enfermería en la perspectiva de clínica ampliada en la U nidad de Cuidados Intensivos.

\section{ABSTRACT}

This articleaims to reflect on nursing care in view of the expanded clinic in the Intensive Care U nit (ICU). The expansion of the clinic aims to think of human beings considering their biological aspects and subjectivity, which is view ed in the light of each particular case through an integral approach, interdisciplinary and shared. J oint efforts by interdisci plinary teams are necessary to modify the ICU setting, where the hegemonic model is historically per petuated. R esponsibility with the individual, their welfare and environment is part of praxis, a fact that enable a change in hegemonic practice for extended clinic.

Descriptors: $\mathrm{H}$ umanization of assistance Intensive care units. Patient care team. N ursing, team.

Title: $\mathrm{N}$ ursing care in the perspective of an expanded dinic in the Intensive Care U nit.

\footnotetext{
a M estre em Enfermagem, D outoranda pelo Programa de Pós-Graduação em Enfermagem F undamental da Escola de Enfermagem de Ribeirão Preto da U niversidade de São Paulo (E ERP-U SP), Professora A ssistente III do D epartamento de Enfermagem da U niversidade Federal dos Vales do Jequitinhonha e M ucuri, Ribeirão Preto, São Paulo, Brasil.

${ }^{b}$ D outor em Enfermagem, Professor D outor da EERP-USP, Ribeirão Preto, São Paulo, Brasil.
} 


\section{INTRODUÇÃO}

A U nidade de T erapia Intensiva (UTI) é um setor hospitalar onde permanecem internados pacientes graves, com ou sem instabilidade hemodinâmica, que necessitam de assistência à saúde ininterrupta nas $24 \mathrm{~h}$ por uma equipe diversificada de profissionais de saúde que, em função do estado deles, tendem a incorporar rapidamente tecnologias, especialmente, relacionadas a equipamentos e medicamentos, necessários e importantes para 0 desenvolvimento do seu trabalho.

Com a constante evolução dos aparatos tecnológicos, os aspectos voltados ao relacionamento interpessoal e humanização da assistência, não necessariamente, têm sido desenvolvidos no cotidiano. Há uma lógica de mercado que vem determinando a crescente necessidade dos profissionais consumirem esta tecnologia, enquanto 0 objeto de trabal ho da equipe é o ser humano que necessita de atenção que vai além desta, devendo ser considerada sua dimensão humana, seus desejos, sua al egria ou tristeza, suas vitórias ou frustrações.

0 cidadão internado pode sentir-se em posição de inferioridade diante dos profissionais, sendo difícil para ele se abrir ou expressar a dor interna, pois o corpo físico e/ ou a identidade pessoal podem estar afetadas. 0 profissional precisa atentar quanto às formas de linguagem utilizadas na transmissão do que está sentindo ou querendo, sendo vigilante com a linguagem corporal para captar os sentimentos deles, assim como se policiar para dizer al go e não passar outra informação com o corpo, mediante expressões faciais, por exemplo(1).

$\mathrm{Na}$ UTI, quanto mais à saúde do cidadão se agrava, o diálogo com ele tor na-se escasso, encontrando, como possível justificativa, sua condição de saúde, a exemplo do estado de coma ou pela preocupação dos profissionais com a prescrição médica, exames bioquímicos e, até mesmo, o banho de leito.

A inversão de valores se perpetua pelo modelo de atenção hegemônico e seus preceitos também encontram força na formação dos profissionais de saúde.

U ma vez preocupados com as tecnologias e manejo das técnicas, os profissionais vão se dei$x$ ando formar e vão formando pessoas incoerentes, muitas vezes, com os seus discursos, promovendo cada vez mais o distanciamento da dicotomia teoria-prática, furtando-se a discussões de modelos que compreendam o cidadão com toda a sua riqueza de existência.

A clínica tradicional, com sua busca de verdade no interior do sujeito, nos traumas e nas triangulações infantis, contrasta com um modelo que concebe o cidadão como verdade precária e que toma o conjunto de suas práticas, como contingentes e historicamente situadas ${ }^{(2)}$.

$H$ á serviços hospitalares que vem fazendo essas discussões, entretanto, a de se atentar para que os seus princípios e diretrizes não estejam apenas no papel e nos discursos, não havendo incorporação da essência das teorias que permeiam os modelos propostos.

U ma proposta de reformulação nas práticas em saúde é a clínica ampliada (CA ) que se destina a ser um instrumento para que os profissionais de saúde e gestores, atuando como equipe interdisciplinar, possam enxergar e atuar na clínica para além dos pedaços fragmentados, sem deixar de reconhecer e utilizar o potencial dos saberes até então instituídos, considerando a complexidade do sujeito e o processo de adoecimento em cada caso(3).

Para implementação de uma clínica ampliada será necessário encarar os riscos subjetivos e sociais, criar possibilidades para construir vínculos consistentes com os cidadãos sendo que estes dispositivos são uma condição para o incremento da eficácia das intervenções clínicas. É possível construí-la partindo do modelo biomédico para os aspectos subjetivos e sociais de cada sujeito, respeitando-se a característica singular de cada caso(4).

A ssim, sugere-se uma re(olhar) para a atenção em UTI onde se contemple o processo saúdedoença do cidadão integralmente, dotado de direitos e deveres, sendo este chamado à responsabilidade, a participar do estabel ecimento do seu destino, tendo autonomia para tomar decisão, considerando seu contexto de vida e que se dê de forma planejada entre o ser viço, profissional e cidadão.

A mudança no trabalho multidisciplinar na UTI voltada a considerar o cidadão em sua plenitude e em seu contexto de vida o beneficia, minimizando os aspectos negativos da internação, como o distanciamento da família, o "fantasma" da morte - mesmo ser facilitador no processo da morte e o morrer - permite o envolvimento do cidadão e familiar no estabelecimento da terapêutica; para os profissionais, possibilita o estreitamento das relações interpessoais com o cidadão e entre seus pares, promove um ambiente menos hostil, permite 
maior flexibilidade nas decisões e resolução de problemas, favorece o crescimento individual e coletivo, pode restringir o uso de tecnologias pesadas e; para a instituição, pode diminuir o tempo de internação, otimizando 0 atendimento das demandas, bem como minimizar a possibilidade de reinternações oriundas de iatrogenias, reduzir os custos por internação devido o estabel ecimento de terapêuticas equivocadas e, até mesmo, minimizar o risco de óbito.

Será necessária a constituição de uma equipe interdisciplinar que realize atividades como 0 acolhimento, vínculo, a escuta, atenção, exercite a autonomia do cidadão e do profissional, desenvolva habilidades de comunicação, enfrentamento de conflitos, decisão compartilhada, como medidas importantes para ampliar a resolução de problemas e promover a CA, sendo que algumas destas medidas vêm sendo discutidas pelo Programa Nacional de Humanização da A tenção e G estão do SU S (PNH) - H umaniza SU $\mathrm{S}^{(3)}$.

Essa reflexão tem como questão principal: como a enfermagem pode manifestar ações e atitudes que favoreçam a reformulação da assistência considerando a inclusão das necessidades do paciente demonstrando compromisso com o mesmo, o estímulo a diferentes práticas de assistência e a co-responsabilidade entre eles, os demais trabaIhadores e os gestores no processo de produção de saúde na UT I? Assim, o estudo tem como objetivo refletir sobre a assistência em enfermagem na perspectiva da CA em UTI. A discussão está fundamentada nos pressupostos da PN H e nos critérios de classificação para UTIS do M inistério da Saúde (M S).

A observação empírica da prática em uma UT I de um hospital durante a super visão de E stágio da Á rea H ospitalar suscitou as inquietações que motivaram essa reflexão.

\section{METODOLOGIA}

Trata-se de um estudo teórico-reflexivo em que a forma e preparação consiste em "formulações discursivas de efeito teorizante com fundamentação sobre a situação global em que se encontra deter minado assunto investigativo ou potencialmente investigativo"(5).

A tentamos que a reflexão enquanto um tipo de estudo não necessita de submissão e consequente aprovação do Comitê de Ética em Pesquisa.

\section{DISCUSSÃO}

O M S classifica as UT Is de acordo com a incorporação de tecnologias, a especialização dos recursos humanos e a área física disponível em tipol, II elll (6).

Na UTI tipo II a equipe deve ser composta por médicos, enfermeiros, fisioterapeutas, técnicos de enfermagem e funcionário exclusivo para 0 serviço de limpeza. D eve dispor de serviços de apoio, recursos materiais pré-estabelecidos e H umanização (climatização, garantia de visitas diárias dos familiares à beira do leito, informações da evolução diária dos cidadãos aos familiares) ${ }^{(6)}$.

A humanização pressupõe que se reconheçam as pessoas que buscam os hospitais à resolução de suas necessidades específicas de saúde, como sujeitos de direitos, observando sua individualidade, ampliando as possibilidades para que possa exercer sua autonomia ${ }^{(7)}$, sendo relevante devido à constituição de um cuidado alicerçado em princípios como a participação social do cidadão, equidade e integralidade da assistência( ${ }^{(8)}$.

Assim, a PNH objetiva efetivar os princípios do SUS nas práticas de atenção e gestão e estimular trocas solidárias entre gestores, trabal hadores e cidadãos para a produção de saúde e de sujeitos, almejando um SUS humanizado, comprometido com a defesa da vida e fortalecido em seu processo de participação democrática e coletiva. U ma de suas propostas consiste na construção da CA norteada por uma política que visa a autonomia e o protagonismo entre os sujeitos, a co-responsabilidade entre eles, o estabelecimento de vínculo solidário, a participação coletiva no processo de gestão e a indissociabilidade entre atenção e gestão(3).

É uma clínica que se abre para perceber e auxiliar o enfermo a construir sua percepção sobre a vida e o adoecimento. Para tal, essa clínica tem que se reconhecer como instrumento de uma instituição médica forte, manipulando saberes e classificações diagnósticas de grande repercussão para quem se submete a ela. Ainda, ela deve desenvolver a competência de usar os poderes que possui e desenvolve na relação terapêutica em favor da autonomia dos cidadãos ${ }^{(9)}$.

Os profissionais necessitam comprometerse em seu papel de cuidador e educador valorizando 0 ser humano conforme suas potencialidades e vivências, transformando a prática em processos dinâmicos, participativos e solidários ${ }^{(10)}$. 
L ogo, o desafio consiste em transpor o campo de certezas, de regularidades mais ou menos seguras, ao campo da imprevisibilidade radical da vida cotidiana, o que implica a decisão pelo saber seguro e preso às estruturas ou pela imprevisibilidade caótica das situações sempre distintas. Assim, uma possibilidade que favorece a CA é o reconhecimento explícito dos limites de qualquer saber estruturado, o que levaria a todo especialista a sempre reconsiderar seus saberes quando diante de qualquer caso concreto, ressaltando a importância em aprender com a variação, a exemplo de valorizar a escuta e saber também perscrutar o caso singular, a fim de decidir ponder ando, ouvindo outros profissionais, expondo incertezas e compartilhando dúvidas ${ }^{(11)}$, numa relação dialógica, ética e solidária voltada a um atendimento integral(8).

A CA remete a reflexão sobre a integralidade que é o próprio caminho que vai transformando os cidadãos e construindo mel horias, buscando uma assistência ampliada, transformadora, centrada no sujeito envolvendo 0 acolhimento, 0 atendimento integral e a valorização da assistência ${ }^{(12)}$.

A assistência de enfermagem tem dimensões biológicas, psicológicas, espirituais, políticas, sociais e econômicas. Florence $\mathrm{N}$ ightingale já trabal hava em prol de melhores condições de atendimento nos hospitais baseando-se em conhecimentos científicos, recebendo apoio de pessoas favoráveis a suas idéias e enfrentando àqueles contrários a elas, imprimindo suas reformas na organização do hospital, nas questões sanitárias e no treinamento e posterior formação da equipe de enfermagem. A titudes simples fizeram a diferença, a exemplo de lavar a roupa de cama e a valorização do diálogo/ atenção com os desvalidos que não aconteciam.

A enfermagem é uma profissão que nasceu vislumbrando o bem-estar do indivíduo na condição da individualidade de cada cidadão em seu modo de andar a vida e o conhecimento científico dessa profissão acompanha essa premissa. Pensar a CA na enfermagem seria resgatar e aplicar por meio de atitudes concretas, o que esta profissão tem a oferecer, posicionando-se cientificamente frente aos demais profissionais, trabalhando para uma assistência efetivamente interdisciplinar, que pressupõe o compromisso e o compartilhamento.

A CA promove uma mudança cultural e de valores sanitários sendo que a enfermagem necessita assumir de fato o seu papel, trabalhando as di- vergências cotidianas entre os saberes e os poderes inerentes ao setor saúde, bem como aos interesses econômicos mercantilistas na área, resgatando e/ ou auxiliando no direcionamento para a participação social, a eqüidade e a integralidade da assistência.

A UTI é um local que favorece o consumo de tecnologias permeadas pelo modelo biomédico hospitalocêntrico. É um local que por manter uma equipe constante pode possibilitar ensaios da CA, com suporte teórico no H umaniza SU S aprimorando aspectos da assistência focadas no cidadão, no profissional eno ambiente, podendo-se utilizar inicialmente das abordagens teóricas dos critérios estabelecidos para classificação das UT I s e da PNH articuladas aos princípios do SUS.

\section{CONSIDERAÇÕES FINAIS}

Diante 0 exposto, entendemos que a assistência de enfermagem na perspectiva da CA em UTI é possível. Os enfermeiros têm muitos desafios pela frente, mas para enfrentá-los, precisamos retomar a perseverança, a deter minação e a atitude que fizeram com que a enfermagem fosse reconhecida.

Consideramos que o tema vem sendo debatido entre profissionais e que há esforços para a amplitude de reflexão e consolidação do conceito e princípios da CA, o que requer mudança na maneira de organização do trabal ho vigente e nas relações humanas. Assim, esperamos que esse estudo possa promover reflexões e discussão no âmbito da UTI para que mecanismos que recomponham a relação singular entre os profissionais e a prática de assistência à saúde baseada na humanização seja a cada dia uma real idade construída e consolidada.

D oravante, 0 ambiente de respeito e flexibilidade, de diálogo e compartilhamento de saberes pela equipe interdisciplinar é fundamental no alcance dos resultados.

\section{REFERÊNCIAS}

1 G odoi AF. H otelaria hospitalar e humanização no atendimento em hospitais: pensando e fazendo. São Paulo: Ícone; 2004.

2 Fonseca T M G, Kirst PG. 0 desejo de mundo: um olhar sobre a clínica. Psicol Soc. 2004;16(3):29-34. 
3 M inistério da Saúde (BR ), Secretaria Executiva, N úcleo T écnico da Política Nacional de Humanização. H umanizaSU S: clínica ampliada e compartilhada [ Internet]. Brasília (DF); 2009 [ citado 2011 fev 11]. Disponível em: http:// bvsms.saude.gov.br/ bvs/ publicacoes/clinica ampliada_compartilhada. pdf.

4 Campos G W S. El filo de la navaja de la función filtro: reflexiones sobre la función clínica en el Sistema Ú nico de Salud en Brasil. Rev Bras E pidemiol. 2005;8(4): 477-83.

5 Revista G aúcha de Enfermagem. I nstruções aos autores. Porto Alegre; 2010 [ citado 2011 fev 11] . D isponível em: http:/ / www.scielo.br/ revistas/ rgenf/ pinstruc.htm.

6 M inistério da Saúde (BR). Portaria no 3432/ G M de 12 de agosto de 1998: estabelece critérios de classificação para as unidades de tratamento intensivo UT I [ I nternet] . Brasília (DF ); 1998 [ citado 2010 jun 10] . Disponível em: http:/ / www.brasilsus.com.br/ legislacoes/gm/ 12837-3432.html.
7 Fortes PAC, M artins CL. A ética, a humanização e a saúde da família. Rev Bras Enferm. 2000;53(n esp):31-9.

8 Casate JC, Correa AK. Humanização do atendimento em saúde: conhecimento veiculado na literatura de enfermagem. Rev Latino-Am E nfermagem. 2005;13 (1):105-11.

9 Cunha G T . A construção da clínica ampliada na A tenção Básica. São Paulo: Hucitec; 2005.

10 Pereira AD, Freitas H M B, Ferreira CL L, M archiori M RCT, Souza M HT, Backes D S. A tentando para singularidades humanas na atenção à saúde por meio do diálogo e acolhimento. Rev G aúcha E nferm. 2010; 31(1):55-61.

11 Campos GW S, A maral M A. A clínica ampliada, a gestão democrática e redes de atenção como referências teórico-operacionais par a a refor ma do hospital. Ciênc Saúde Colet. 2007;12(4):849-59.

12 Fontoura RT, M ayer CN. U ma breve reflexão sobre a integralidade. Rev Bras E nferm. 2006;59(4):532-7.

\section{Endereço da autora / Dirección del autor / Author's address:}

L uciana de Freitas Campos

Rua I saías J osé Fer reira, 1380, J ardim Palmares

14092-453, Ribeirão Preto, SP

E - mail: camposlf@gmail.com
Recebido em: 13/09/2010

A provado em: 05/ 02/ 2011 